This is the author's final, peer-reviewed manuscript as accepted for publication. The publisher-formatted version may be available through the publisher's web site or your institution's library.

\title{
The effects of the intergenerational transmission of family emotional processes on conflict styles: the moderating role of attachment
}

Joyce A. Baptist, David E. Thompson, Aaron M. Norton, Nathan R. Hardy, Chelsea D. Link

\section{How to cite this manuscript}

If you make reference to this version of the manuscript, use the following information:

Baptist, J. A., Thompson, D. E., Norton, A. M., Hardy, N. R., \& Link, C. D. (2012). The effects of the intergenerational transmission of family emotional processes on conflict styles: The moderating role of attachment. Retrieved from http://krex.ksu.edu

\section{Published Version Information}

Citation: Baptist, J. A., Thompson, D. E., Norton, A. M., Hardy, N. R., \& Link, C. D. (2012). The effects of the intergenerational transmission of family emotional processes on conflict styles: The moderating role of attachment. American Journal of Family Therapy, 40(1), 56-73.

Copyright: @ Taylor \& Francis Group, LLC

Digital Object Identifier (DOI): doi: 10.1080/01926187.2011.575030

Publisher's Link: http://www.tandfonline.com/doi/abs/10.1080/01926187.2011.575030

This item was retrieved from the K-State Research Exchange (K-REx), the institutional repository of Kansas State University. K-REx is available at http://krex.ksu.edu 
In-press in the American Journal of Family Therapy

\author{
The Effects of the Intergenerational Transmission of Family Emotional Processes on Conflict Styles: The \\ Moderating Role of Attachment \\ Joyce A. Baptist, David E. Thompson, Aaron M. Norton, Nathan R. Hardy, Chelsea D. Link \\ Kansas State University
}

\begin{abstract}
This study of 203 emerging adults investigated the moderating role of attachment on the intergenerational transmission of the effects of family emotional processes (enmeshment and disengagement) on adult offspring's conflict management. Results indicated that higher levels of perceived disengagement led to more use of hostile and volatile and lower use of validating conflict styles. Results further indicated that attachment moderated the effects of disengagement on hostile and volatile but not validating styles. High levels of anxiety exacerbated the effects of disengagement while low levels of avoidance buffered the effects of disengagement. Clinical and research implications are discussed.

Keywords: disengagement, enmeshment, cohesion, conflict style, attachment

Joyce A. Baptist, Ph.D., and David E. Thompson, Ph.D., Assistant Professors, Aaron M. Norton, BS, Nathan R. Hardy, BS, and Chelsea D. Link, BS, graduate students, School of Family Studies and Human Services, Kansas State University. Correspondence concerning this article should be addressed to Joyce A. Baptist, FSHS, 302 Justin Hall, Kansas State University, Manhattan, KS 66506. Email: jbaptist@ksu.edu. Phone: 7855326891.
\end{abstract}

A key element of successful interpersonal relationships is the use of constructive conflict management, such as problem-solving, compromise, affection, humor, and apology (Cummings, \& Davies, 2002). On the other hand, destructive conflict management such as using threats, hostility, insults and withdrawal on the other hand, can impair relationships. Research shows that behaviors can be transmitted across generations as children learn these behaviors as ways to manage conflict and communicate needs from observing and experiencing relational patterns in their families-of-origin (Whitton, Waldinger, Schulz, Allen, Crowell, \& Hauser, 2008). Parental interpersonal conflict, which reflects the underlying emotional tension in the family (Kerr \& Bowen, 1981), sets the tone for how offspring interpret conflict within the family system (Harold, Shelton, Goeke-Morey, \& Cummings, 2004). As offspring recreate their family's emotional tensions in their own adult relationships, they are said to inevitably recreate the (dys)function of emotional processes from previous generations. While extensive research has documented the negative impact of dysfunctional family relationships on offsprings' adult interpersonal relationship functioning (e.g., Amato \& Keith, 1991), studies have further suggested that secure attachment can buffer the effects of difficult family experiences (e.g., Beeghly \& Cicchetti, 1996; Crowell, Trebouz, \& Broakmeyer, 2009). Specifically, a child's secure attachment was found to be a protective mechanism against the negative impact of dysfunctional relationships in one's family-of-origin. Consequently, adult secure attachment could act as a protective barrier to the negative effects while adult insecure attachment could exacerbate these effects.

The dynamic nature of adult attachment (Bowlby, 1969) can further increase the likelihood that attachment can affect interpersonal relationships differently across time. Thus, negative experiences in one's family-of-origin can negatively impact interpersonal relationships more during childhood than during adulthood if the adult had the opportunity to develop a more secure attachment base that can buffer negative family effects. In identifying the factors that influence an adult's conflict style, it is then insufficient to only consider how emotions were managed in the family-of-origin or the individual's attachment security. How the adult's attachment security or other individual related states of mind interact with the effects of family-of-origin emotional processes needs to be considered. It is further insufficient to merely examine how behaviors are transmitted across generations but to examine how the management of distressful emotions informs later behaviors. More importantly, how adult attachment can buffer against negative family-of-origin processes can have implications for clinical practice. Considering that this link has not been examined in previous studies, this study examined the moderating role of adult attachment on the effects of the intergeneration transmission of family-of-origin emotional processes on conflict styles in interpersonal relationships.

The Intergenerational Transmission of Emotional Processes

The idea that behaviors both destructive and constructive in the family can be modeled and carried forward by offspring into their adult relationships is supported by social learning theory (Bandura, 1977) and intergenerational theories such as Bowen theory (Bowen, 1966). The negative effects of intergenerational 
transmission of family interactions is supported by studies such as Whitton et al.(2008) where hostile interactions in families-of-origin such as contemptuous affect and emotional invalidation replicated in adult relationships, predicted relationship decline. Thus, the intergenerational transmission process argues that aggression in adult intimate relationships is a by-product of dysfunctional emotional processes that has its origin in generations past.

Interactional patterns inherited through this means serve to maintain a pattern of functioning across generations.

Families that are unable to manage intense emotions can experience extreme levels of closeness (enmeshed) or separateness (disengaged) (Olson, Russell, \& Sprenkle, 1989). These families are (unable) to emphasize togetherness, emotional closeness, or simultaneously enjoy and permit personal space. Extreme levels of closeness or enmeshment reflect relationships that are highly dependent, emotionally reactive, and demand loyalty. Extreme levels of separateness or disengagement reflect relationships that lack mutual support, involvement and emotional connection. Such families are more apt to avoid dealing with conflictual situations or project intense emotions. Not only does family-of-origin functioning impact how individuals interact in their adult relationships, hostile interactions in the family-of-origin were found to be more influential on adult relationships than positive engagement, such as being attuned to feelings, and validating the other's perspective (Whitton et al., 2008). Other studies found similar results suggesting that dysfunctions in families-of-origin are related to difficulties with problem-solving communication and global distress in adult intimate relationships (e.g., Harrington \& Metzler, 1997). Given this direct relationship between family-of-origin functioning and conflict in adult relationships, we examined the direct effects of the perceived levels of enmeshment and disengagement in families-of-origin on adult interpersonal conflict.

\section{Conflict Styles in Relationships}

One of the most helpful schemas for looking at inter-partner conflict was proposed by Gottman and associates, developed through years of observation of couples in conflictual settings (e.g., Gottman \& Levenson, 2000). Three functional or regulated styles of conflict were proposed which relate to more successful relational outcomes, and are distinguished by the degree of willingness of the partners to influence each other through positive dialogue and interaction, and one unregulated or dysfunctional style. The first regulated conflict style is avoidant, which refers to a preference to minimize or even avoid conflict and conflictual interaction with the hope that the issue at hand will resolve (or at least minimize) itself over time, or the couples may simply agree to disagree on the issue without pressing for a resolution. Couples utilizing the second regulated style, validating, strive to ensure that each party feels heard and appreciated and work toward mutually satisfactory outcomes. In contrast, partners preferring the third regulated style, volatile, will frequently engage in active and even passionate disagreement. While Gottman (1999) stated that no (regulated) style is superior to another, research indicates that couples who are matched (both partners utilizing the same conflict styles) and who utilize a more validating style tend to be more relationally satisfied (Busby \& Holman, 2009).

While the three regulated styles can facilitate varying degrees of positive outcomes for the parties in a relationship, the unregulated hostile style is destructive and marked by couples engaging in contemptuous and deprecatory conflict, reducing positive affect and relational stability between the partners (Gottman, 1994). Studies indicate that any couple in which even one partner is hostile is likely to be more problematic and less stable than those in which both partners manifest one of the regulated forms of conflict styles (e.g., Gottman \& Levenson, 2000). Gottman's proposal that the three regulated conflict styles are equivalent was not replicated in Busby and Holman's (2009) study that found the validating style associated with substantially better results on relationship outcome measures than volatile and avoiding styles. Consequently, we differentiate between the validating style that is constructive, and the avoiding, volatile and hostile styles that are less constructive.

\section{Adult Attachment}

Representations and expectations of self and others developed via direct repetition of (dys)functional emotional processes and family-of-origin dynamics are said to influence attachment styles in adult relationships (Ainsworth \& Bowlby, 1991; Bowen, 1966). These working models of self and others while once believed to be stable over the lifespan have been found to change overtime. Specifically, attachment levels were found to change overtime from late adolescence to early adulthood becoming more secure (e.g., Crowell, Treboux \& Waters, 2002). The fluctuations in attachment levels led to the conceptualization of attachment as having trait and state components (Fraley \& Brumbaugh, 2006). Compared to trait components, state components are more likely to fluctuate as new life events and information is accommodated. Attachment levels are said to vary depending on changes in life events and circumstances that are emotionally significant (Bowlby, 1969), or that activate different states of mind or attachment styles (e.g., Baldwin, Keelan, Fehr, Enns, \& Koh-Rangarajoo, 1996). Furthermore, vulnerabilities such as parental divorce and personal pathology that are associated with insecure attachment can reduce attachment stability (Davila, Burge, \& Hammen, 1997). Individuals who possess less stable attachment models in particular are 
more amenable to change. The dynamic feature of attachment infers that adult attachment can change over time influencing relationships differently at different points in time.

Individuals whose attachment evolve becoming more secure develop mental and affective autonomy that facilitates the process of differentiation, thus allowing more accurate identification of maladaptive processes and the ability to consciously decide to not replicate these processes (Bowen 1966). Insecure individuals develop lower levels of differentiation that make it more difficult for them to separate from family processes, thus are more inclined to automatically reenact and pass on these processes to future generations. Changes in attachment and its implications for relationships make it necessary to consider how present attachment levels influence relationship functioning.

\section{Attachment and Conflict}

Adult attachment is defined on two relatively orthogonal dimensions: anxious and avoidant (Brennan, Clark, \& Shaver, 1998). Individuals who develop non-effective processing of emotionally evocative information are said to develop high levels of anxious or avoidant attachment that reflect insecure attachment (Brennan et al., 1998). Avoidant individuals do not believe that others will respond to their needs for intimacy, hence they fear closeness. These individuals are likely to dismiss and reject intimacy with and dependency on others when emotionally provoked to protect themselves from rejection and disappointment. The avoidant dimension of attachment is said to be responsible for the regulation of attachment-related behaviors such as seeking support versus retracting from attachment figures in anxiety provoking situations as in the case of conflict (Fraley \& Shaver, 2000).

Low perception of self-worth among anxiously attached individuals makes them prone to seek closeness with others when emotionally provoked. These individuals are likely to be obsessed with relationships and worry about the availability, responsiveness, and attention that they depend on to establish self-worth (Bartholomew \& Horowitz, 1991). They are said to adopt emotionally-focused coping styles that amplify distress. They are apt to more closely monitor emotional closeness placing greater weight on cues of rejection than on cues of support (Fraley \& Shaver, 2000). When faced with relational conflict, their distress leads them to resort to behaviors that aggravate the conflict (Simpson, Rholes, \& Philips, 1996). Overall, insecurely attached individuals tend to distort attachment-related information, such as exaggerating feelings of abandonment during a conflict that impeded their ability to be open and flexible or to recognize positive conciliatory behaviors from their partners.

Individuals who develop working models that facilitate effective processing of emotionally evocative information are said to be secure in their attachment levels (Bowlby, 1988). These individuals generally score low on anxious and avoidant attachment. They are believed to have greater cognitive and emotional autonomy, allowing them to decipher between destructive and constructive behaviors and consciously choose the behaviors they adopt. Securely attached individuals are further said to be more effective at regulating emotions, thus are less inclined to automatically replicate behaviors that are maladaptive.

The role of attachment in moderating the intergenerational transmission of aggressive behaviors is supported by Hare, Miga and Allen's (2009) study that examined transmission from parent to adolescents. Their study found that the transmission of aggressive behaviors was strong for adolescents with low attachment security but not with high attachment security five years post exposure to the aggressive behavior. Their study supports the idea that attachment security buffered transmission of destructive behaviors across generations.

To extend the current literature, we examined how adult attachment levels moderate the effects of negative family-of-origin emotional processes on the development of conflict styles in adult relationships. We hypothesized that how individuals perceive the management of emotions in their families-of-origin, reflected in the degree of closeness (enmeshment) and separateness (disengagement) among family members will have a direct impact on how individuals react to emotionally evocative situations such as conflict in their adult relationships. We further hypothesized that the effects of family-of-origin emotional processes on adult interpersonal relationships will be moderated by the individual's adult attachment levels. In summary, we hypothesized the following as depicted in Figure 1:

H1: Higher levels of perceived enmeshment and disengagement in families-of-origin will be associated with higher use of hostile, volatile and avoiding conflict styles and lower use of validating conflict style. $\mathrm{H} 2$ : Attachment levels will moderate the relationship between perceived enmeshment and disengagement in families-of-origin and conflict styles.

\section{Participants and Procedure}

\section{Methods}

Participants were students from two general education classes at a large public university in the Midwest. Students were invited to voluntarily participate in this study for extra class credit. Students who chose not to participate were provided an alternative assignment for extra credit. This study was approved by the university's Institutional Review Board. Students were sent a link to the survey electronically. A total of 203 students provided 
completed the survey. This study only included students of the emerging adult age group, 18 to 25 ( $N=190: 37$ males and 153 females). The mean age of the sample was $20.86(S D=1.27)$. Of this number, 76 were single and 114 were partnered (98 dating, 14 cohabitating, 2 married). Participants included 166 White/European, 10 Black/African descent, 4 Non-White Hispanic/Latino, 3 Asian, 1 American Indian/Alaskan Native, and 6 with two or more races.

\section{Measurement Instrument}

Family cohesion. The Family Adaptation and Cohesion Scale -IV (FACES-IV) cohesion subscales were used to measure enmeshment (7 items) and disengagement (7 items) in families-of-origin (Olson \& Gorall, 2006). Enmeshment measures the family members' level of dependence on one another and level of emotional reactivity (e.g., "We spend too much time together"). Disengagement measures family members' reliance on one another for support (e.g., "Family members seem to avoid contact with each other when at home"). Participants rated items using a 5-point Likert scale from 1 (Strongly disagree) to 5 (Strongly agree) to describe their families and its members when they were still living at home prior to enrolling in college. Scale items were totaled and higher values indicated higher levels of perceived enmeshment and disengagement, or lower levels of cohesion in their families-of-origin. The scales proved to be valid, with reliability of .87 for disengaged and .77 for enmeshed (Olson, 2011). The coefficient alphas for this sample were .84 (disengaged) and .76 (enmeshed).

Conflict styles. Four short scenarios each describing Gottman and Levenson's (2000) volatile, avoiding, validating and hostile relationships adopted from Holman and Jarvis (2003), was used in this study. For example, volatile conflict style was described as "In our relationship, conflicts may be fought on a grand scale, and that is okay, since our making up is even grander. We have volcanic arguments, but they are just a small part of a warm and loving relationship. Although we argue, we are still able to resolve our differences. In fact, our passion and zest for fighting actually lead to a better relationship, with a lot of making up, laughing, and affection." Participants were asked to indicate how often each scenario described the conflict in their relationships using a 5-point Likert scale from 1 (Never) to 5 (Very often). Higher scores on each scenario indicated higher use of the conflict style described.

Attachment. The Experiences in Close Relationships-Revised scale (ECR-R, Fraley, Waller, \& Brennan, 2000) was used to measure the two dimensions underlying adult attachment: attachment avoidant (18 items) and attachment anxiety (18 items). The attachment anxiety subscale measured the fear of rejection and abandonment (e.g., "I worry about being abandoned"). The attachment avoidant subscale tapped discomfort with closeness in intimate relationships (e.g., "I prefer not to show a partner how I feel deep down"). Participants rated items using a 7-point Likert scale from 1 (Strongly disagree) to 7 (Strongly agree), according to how they generally experienced romantic relationships. Scale items were totaled and higher values represented higher levels of anxious and avoidant attachment, or insecure attachment. Reliability estimates of the ECR-R were found to be satisfactory and comparable to those of the original ECR items (Brennan et al., 1998), the coefficient alphas of which were always near or above .90. The ECR-R test-retest correlations were reported to range from .93 to .95 (Fraley et al., 2000). The coefficient alphas for this sample were .93 (anxiety) and .94 (avoidance).

\section{Preliminary Analyses}

\section{Results}

Means and standard deviations for all variables are presented in Table 1 together with the correlation coefficients among the variables. Sex and relationship status were dummy coded: 1 for male and single, and 2 for female and partnered. Correlation results indicated that individuals who reported high anxious and avoidant attachment were more likely to perceive their families-of-origin as more disengaged and enmeshed. These individuals were more likely to use hostile and avoiding conflict styles and were less validating. Individuals who perceived their families-of-origin as disengaged and enmeshed were more likely to resolve conflict using volatile and hostile methods and were less validating.

MANOVAs were conducted to examine the differences in conflict styles, attachment levels and perceived levels of family-of-origin enmeshment and disengagement between men and women and between single and partnered participants. Results indicated significant main effects for sex, Wilks' Lambda $=.823, F(8,179)=4.80, p$ $<.001, \eta_{\mathrm{p}}{ }^{2}=.18$, and relationship status, Wilks' Lambda $=.772, F(8,179)=6.61, p<.001, \eta_{\mathrm{p}}{ }^{2}=.23$. Interaction between sex and relationship status was not significant. Univariate $F$-tests indicated that men scored higher on avoidant attachment, $F(1,186)=5.14, p=.024, \eta_{\mathrm{p}}{ }^{2}=.03$, used more avoiding, $F(1,186)=5.35, p=.022, \eta_{\mathrm{p}}{ }^{2}=.03$, and hostile, $F(1,186)=13.01, p<.001, \eta_{\mathrm{p}}{ }^{2}=.07$, conflict styles, and perceived their families-of-origin as more disengaged, $F(1,186)=7.30, p=.008, \eta_{\mathrm{p}}{ }^{2}=.04$, and enmeshed, $F(1,186)=21.13, p<.001, \eta_{\mathrm{p}}{ }^{2}=.10$, compared to women. In addition, single participants reported higher levels of anxious, $F(1,186)=16.78, p<.001, \eta_{\mathrm{p}}{ }^{2}=.08$, and avoidant attachment, $F(1,186)=32.66, p<.001, \eta_{\mathrm{p}}{ }^{2}=.15$, and used more hostile conflict style, $F(1,186)=3.98, p=$ $.048, \eta_{\mathrm{p}}{ }^{2}=.02$, compared to partnered participants. 
Overall, it appears that men in this sample were more avoidant in their attachment, used more avoiding and hostile conflict styles and perceived their families-of-origin as more disengaged and enmeshed compared to women. In addition, participants who were single appeared to be more insecure in their attachment and used more hostile conflict style compared to participants who were partnered.

\section{Primary Analyses}

To test the hypothesis that perceived levels of disengagement and enmeshment in families-of-origin influenced subsequent relational conflict styles via the moderating role of attachment, hierarchical regressions were performed. The first set of regressions included control variables (sex and relationship status) in Step 1 followed by the independent variables (perceived levels of disengagement and enmeshment in families-of-origin) in Step 2. The dependent variables were the conflict styles: hostile, volatile, validating and avoiding. The second set of regressions included the control variables (sex and relationship status) in Step 1 followed by the independent variables (perceived levels of disengagement and enmeshment in families-of-origin) in Step 2, followed by the moderators (anxious and avoidant attachment) in Step 3 and finally the interactions between the independent variables and the moderators in Step 4. Results of Steps 2 and 4 are presented in Table 2 as Model 1 and 2. Model 1 tested H1 and Model 2 tested H2. Significant moderating effects were further examined using Hayes and Mattes (2009) MODPROBE version 1.3. Variables were mean-centered prior to analysis.

Regression results partially supported H1. Perceived levels of disengagement in families-of-origin and not perceived enmeshment levels in families-of-origin was associated with increased use of hostile, $t(185)=4.20, p<$ .001 , and volatile, $t(185)=2.37, p=.02$, conflict styles and reduced use of validating conflict style, $t(185)=-2.51, p$ $=.01$. Perceived levels of cohesion in families-of-origin was not associated with the use of avoiding conflict styles by emerging adults. Perceived cohesion levels in families-of-origin accounted for $10 \%$ of the use of hostility, $5 \%$ of volatility and $5 \%$ of validating styles.

Regression results partially supported $\mathrm{H} 2$. Anxious attachment moderated the effect of perceived disengagement in families-of-origin on the use of hostile conflict style, $t(179)=3.02, p=.003$. Post-hoc probing indicated that the moderating effect of anxious attachment accounted for $5 \%, p<.001$ change in hostility. The moderating effect of anxious attachment is only significant at the mean, $\mathrm{B}=.052, t(182)=3.28, p=.001$, or $1 S D$ above the mean, $\mathrm{B}=.096, t(182)=4.73, p<.001$, and not at $1 S D$ below the mean as illustrated in Figure 2. High levels of anxious attachment increased the effect of family-of-origin disengagement by increasing the use of hostility to manage conflict.

Avoidant attachment moderated the effect of perceived disengagement in families-of-origin on the use of volatile conflict style, $t(179)=-2.0, p=.047$. Post-hoc probing indicated that the moderating effect of avoidant attachment accounted for $1 \%, p=.098$ change in volatility. The moderating effect of avoidant attachment is only significant at the mean, $\mathrm{B}=.045, t(182)=2.26, p=.025$, or $1 S D$ below the mean, $\mathrm{B}=.069, t(182)=2.83, p=$ .005 , and not at $1 S D$ above the mean as illustrated in Figure 3. Low levels of avoidant attachment reduced the effect of family-of-origin disengagement by decreasing the use of volatility to manage conflict.

Anxious attachment moderated the effect of perceived enmeshment in families-of-origin on the use of validating conflict style, $t(179)=2.24, p=.026$. Post-hoc probing did not find any significant interaction relationship between anxious attachment and family-of-origin disengagement.

\section{Discussion}

This study investigated the moderating role of attachment on the relationships between the effects of perceived levels of emotional functioning (enmeshment and disengagement) in families-of-origin and adult offspring's conflict styles. Perceived levels of disengagement in families-of-origin influenced conflict styles. As higher levels of disengagement were perceived in families-of-origin, higher use of hostile and volatile and lower validating styles were reported. It is possible that the average mean score of enmeshment in this sample was too low to detect any significant effect although the direction of association between perceived enmeshment and conflict styles was similar with that of perceived disengagement.

The relationship between family disengagement and conflict style was further influenced by the individual's level of attachment. Individuals who were anxiously attached and who perceived their families-oforigin as more disengaged were more likely to experience intensification in hostility during conflict, especially when levels of anxiety were at or above average levels. Individuals who were less avoidant in their attachment and perceived their families-of-origin as disengaged, on the other hand, were less likely to be volatile in their conflict. This was especially true for those who scored at or below the average level of avoidant attachment.

The increased use of hostile and volatile conflict style by individuals who perceived high levels of disengagement in their families-of-origin could be a result of having reduced emotional involvement and interaction in their families-of-origin, as well as less opportunity to learn positive means by which to manage conflict. Perhaps issues in the disengaged families were not dealt with until they reached a point of such emotional intensity that 
family members reacted with a high degree of negative affect, utilizing more hostile or volatile forms of conflict. It is further possible that a perceived lack of close emotional connection within the family resulted in its members sensing their emotional needs as not being met unless one engaged in more forceful or attention getting means, such as using a hostile or volatile conflict style.

In a similar vein, individuals who experience high disengagement in their families-of-origin are less likely to be amenable to constructive forms of managing conflict such as validating due to the lack of role modeling. Having not learned to connect with others in a meaningful way can challenge an individual's ability to meet the needs of others by striving for a win-win situation during a conflict.

In addition to the effects of perceived emotional processes of families-of-origin, an individual's state of mind such as attachment security plays an important role in determining conflict management behavior. More specifically, results suggest that individuals who were less avoidant in their attachment were less likely to be volatile. These individuals, being more secure, were apt to manage conflict constructively, thus buffering the effects of having had disengaged families-of-origin. Their positive working models of self and others allow them to process emotional content objectively and better differentiate between constructive and destructive behaviors. The higher degree of differentiation of securely attached individuals further facilitates emotional autonomy that can help prevent the replication of harmful interaction patterns observed in families-of-origin.

On the other hand, individuals who were more anxious in their attachment, and experienced high levels of disengagement in their families-of-origin, reported escalated use of hostility. Typically needing connection and reassurance in relationships, anxious individuals who grew up in highly disengaged families not only lack meaningful emotional connections but are prone to experience rejection. These individuals are known to amplify distress and resort to emotionally-focused coping styles that can aggravate conflict. Hostile expression might be used as a means of provoking interaction even if the interaction is harmful to the relationship. Any form of interaction can be reassuring to an anxious individual. As such, attention getting hostility may be preferable to such an individual rather than feeling disconnected or unnoticed. Furthermore, these individuals might perceive destructive conflict behavior as normative. Their lack of differentiation that curtails their degree of self-reliance could further explain the propensity to simply replicate conflict management behaviors that match that of their families-of-origin.

Perceived levels of cohesion in families-of-origin was not significantly associated with the use of avoiding conflict styles by emerging adults. While an avoiding conflict style would seemingly be utilized by those from families marked by high degrees of disengagement, this was not supported by the data. This may be a cohort effect attributed to the importance emerging adults attach to maintaining the relationships that they are just now learning to form and keep. It is therefore possible that emerging adults in this study, many of whom are away from home for the first time, may be willing to use conflict avoidance as a means of attempting to maintain peace in order to maintain current relationships.

Another noteworthy finding was the lack of attachment's influence on the relationship between perceived family-of-origin disengagement level and validating conflict styles. This lack of influence suggests that an individual's use of validating during conflict is determined by their experiences in their families-of-origin. Improvement in an individual's attachment security in adulthood does not act as a buffer. This finding warrants further investigation. In fact, results suggest that attachment security only buffers the impact of family-of-origin emotional processes by reducing volatility during conflict.

In addition the results indicate that the volatile style might be different from validating and avoiding styles and as such should not be clustered together in the same group as suggested by Gottman (1994). These results support Busby and Holman's (2009) study that found volatile conflict style to be destructive unlike validating.

\section{Limitations of this Study}

The generalizability of the study is limited as the participants were emerging adults from a Midwestern university. The convenience method employed in this study was an additional factor that limits generalizability. Self-report data such as that used in this study is vulnerable to mono-method biases and social desirability. Studies that elicit partners' perception could more fully capture the attachment and conflict styles of the participants.

\section{Clinical and Research Implications}

The results of this study support the need to use integrative approaches in therapy when treating interpersonal conflict. The use of multiple models can better allow therapists to treat the multiple factors that influence conflict in relationships -- family-of-origin emotional processing and adult attachment security. Intergenerational models, such as Bowen and Contextual therapy, can help clients identify how their childhood experiences of anxiety in their families-of-origin inform their expectations in their current relationships and explain their propensity to engage in conflict resolution behaviors that are destructive to their relationships. This process of contextualizing clients' childhood experiences and making sense of those experiences can help with the 
differentiation process that can in turn build attachment security. Integrating this work with therapy models that focus on the working models of self, such as Emotionally-Focused Therapy, Imago Relationship Therapy and Virginia Satir's experiential interventions can facilitate increasing attachment security and emotional bonding in couples. Considering the interrelations between emotional processing in families-of-origin and insecurities in attachment will allow therapists to better identify and treat the root of the destructive conflict behavior.

Understanding the motivations or unmet needs that are communicated by the conflict behavior can then be followed up with treatment that focuses on obtaining those needs in more constructive ways. Thus, unlearning a destructive conflict style involves more than merely changing one's behavior. It needs to begin with identifying the unmet needs that are communicated by the conflict behavior.

As a cohort effect is a likely cause for the lack of association between family-of-origin disengagement and avoidant conflict style, future studies would benefit from utilizing a cross-sectional population to more accurately determine the association between the two variables. This study utilized survey data to determine family-of-origin cohesion, attachment levels, and conflict styles of only one partner. Future studies could benefit from conducting observations to more accurately determine the levels of each variable. Studies that elicit the emotional processes in the couple relationship could better identify the influences on conflict styles by differentiating between the effects from families-of-origin and partner effects.

\section{References}

Ainsworth, M. D. S., \& Bowlby, J. (1991). An ethological approach to personality development. The American Psychologist, 46, 333-341.

Amato, P.R., \& Keith, B. (1991). Consequences of parental divorce for children's well-being: A meta-analysis. Psychological Bulletin, 110, 26-46.

Baldwin, M. W., Keelan, J. P., Fehr, B., Enns, V., \& Koh-Rangarajoo, E. (1996). Social-cognitive conceptualization of attachment working models: Availability and accessibility effects. Journal of personality and social psychology, 71, 94-109.

Bandura, A. (1977). Social learning theory. Englewood Cliffs, NJ: Prentice-Hall.

Bartholomew, K., \& Horowitz, L. M. (1991). Attachment styles among young adults: A test of a four-category model. Journal of Personality and Social Psychology, 61, 226-224.

Beeghly, M., \& Cicchetti, D. (1996). Child maltreatment, attachment, and the self system: Emergence of an internal state lexicon in toddlers at high social risk. In M.E. Hertzig \& E.A. Farber (Eds.), Annual progress in child psychiatry and child development (pp. 127-166). New York: Brunner/Mazel.

Bowen, M. (1966). The use of family theory in clinical practice. Comprehensive Psychiatry, 7, 345-374.

Bowlby, J. (1969). Attachment and loss: Attachment (Vol. I). New York: Basic Books.

Bowlby, J. (1988). Attachment and loss: Loss, sadness and depression (Vol. III). New York: Basic Books.

Brennan, K. A., Clark, C. L., \& Shaver, P. R. (1998). Self-report measurement of adult attachment: An integrative overview. In J. A. Simpson, \& W. S. Rholes (Eds.), Attachment theory and close relationships (pp. 46-76). New York: Guildford Press.

Busby, D. M., \& Holman, T. B (2009). Perceived match or mismatch on the Gottman conflict styles: Associations with relationship outcome variables. Family Process, 48, 531-545.

Crowell, J. A., Treboux, D., \& Broakmeyer, S. (2009). Parental divorce and adult children's attachment representations and marital status. Attachment and Human Development, 11, 87-101.

Crowell, J. A., Treboux, D., \& Waters, E. (2002). Stability of attachment representations: The transition to marriage. Developmental Psychology, 38, 467-479.

Cummings, E. M., \& Davies, P. T. (2002). Effects of marital conflict on children: Recent advances and emerging themes in process-oriented research. Journal of Child Psychology and Psychiatry, 43, 31-63.

Davila, J., Burge, D., \& Hammen, C. (1997). Why does attachment style change? Journal of Personality and Social Psychology, 73, 826-838.

Fraley, R.C., \& Shaver, P. R. (2000). Adult Romantic Attachment: Theoretical Developments, Emerging Controversies, and Unanswered Questions. Review of General Psychology, 4, 132-154.

Fraley, R. C., \& Brumbaugh, C. C. (2006). Transference and attachment: how do attachment patterns get carried forward from one relationship to the next? Personality and Social Psychology Bulletin, 32, 552-560.

Fraley, R. C., Waller, N. G., \& Brennan, K. A. (2000). An item response theory analysis of self-report measures of adult attachment. Journal of Personality and Social Psychology, 78, 350-365.

Gottman (1999). The marriage clinic: A scientifically based marital therapy. New York: Norton.

Gottman, J. M. (1994). What predicts divorce? Hillsdale, NJ: Erlbaum. 
Gottman, J. M., \& Levenson, R. W. (2000). The timing of divorce: Predicting when a couple will divorce over a 14 year period. Journal of Marriage and Family Therapy, 62, 737-745.

Hare, A. L., Miga, E. M., \& Allen, J. P. (2009). Intergenerational transmission of aggression in romantic relationships: The moderating role of attachment security. Journal of Family Psychology, 23, 808-818.

Harold, G. T., Shelton, K. H., Goeke-Morey, M. C., \& Cummings, E. M. (2004). Marital conflict and child adjustment: Prospective longitudinal tests of the mediating role of children's emotional security about family relationships. Social Development, 13, 350-376.

Harrington, C. M., \& Metzler, A. E. (1997). Are adult children of dysfunctional families with alcoholism different from adult children of dysfunctional families without alcoholism? A look at committed, intimate relationships. Journal of Counseling Psychology, 44, 102-107.

Hayes, A. F., \& Mattes, J. (2009). Computational procedures for probing interaction in OLS and logistic regression: SPSS and SAS implementations. Behavior Research Methods, 41, 924-936.

Holman, T. B., \& Jarvis, M. O. (2003). Hostile, volatile, avoiding, and validating couple-conflict types: An investigation of Gottman's couple-conflict types. Personal Relationships, 10, 267-282.

Kerr, M. E., \& Bowen, M. (1981). Family evaluation: An approach based on Bowen theory. New York: Norton.

Olson, D. H. (2011). FACES IV and the Circumplex Model: Validation study. Journal of Marital and Family Therapy, 37, 64-80.

Olson, D. H., Russell, C. S., \& Sprenkle, D. H. (1989). Circumplex model: Systemic assessment and treatment of families. New York: Haworth Press.

Olson. D. H., \& Gorall, D. M. (2006). FACES IV and the Circumplex Model. Roseville, MN: Life Innovations.

Simpson, J., Rholes, W., \& Phillips, D. (1996). Conflict in close relationships: An attachment perspective. Journal of Personality and Social Psychology, 71, 899-914.

Whitton, S. W., Waldinger, R. J., Schulz, M. S., Allen, J. P., Crowell, J. A., \& Hauser, S.T. (2008). Prospective associations from family-of-origin interactions to adult marital interactions and relationship adjustment. Journal of Family Psychology, 22, 274-286.

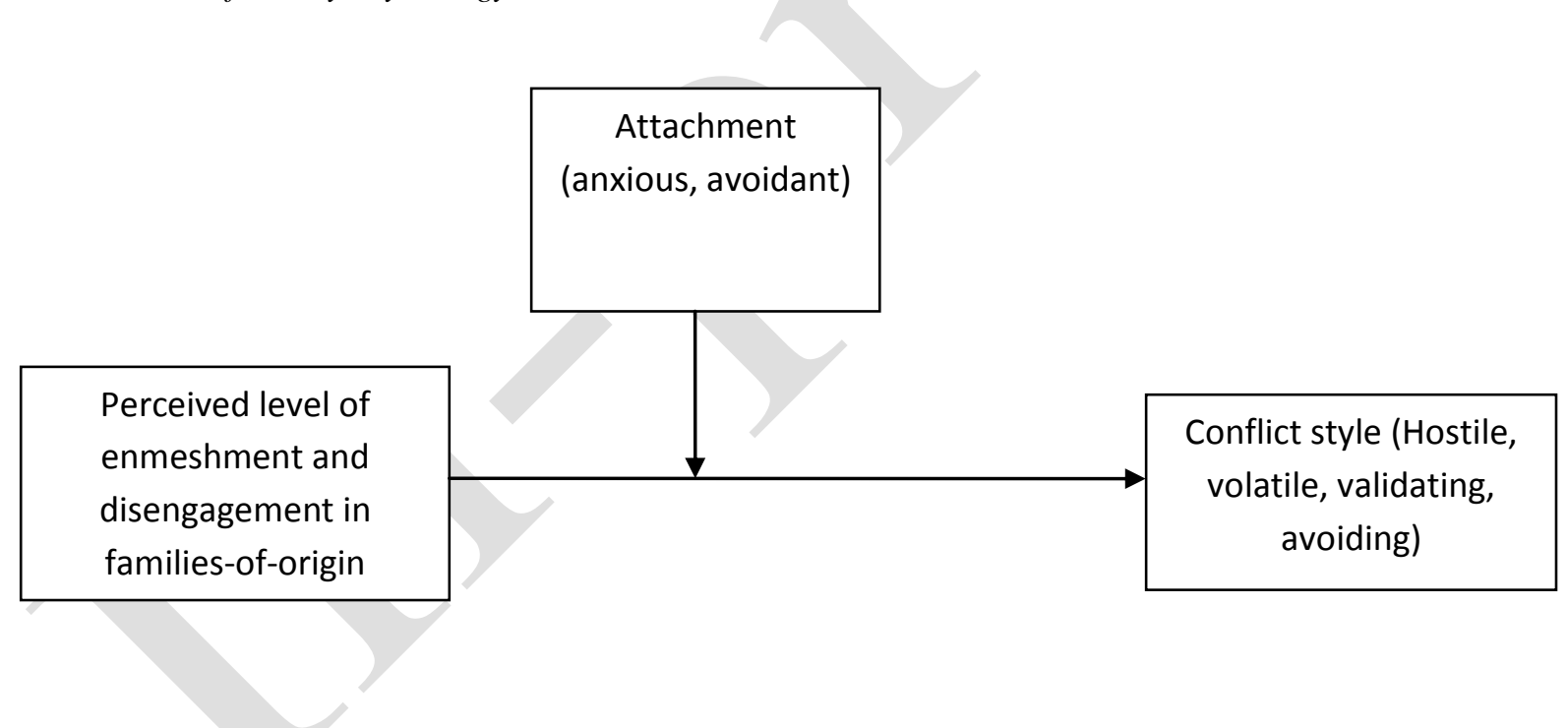

Figure 1. The Proposed Moderating Effect of Attachment on the Relationship between Perceived Levels of Enmeshment and Disengagement in Families-of-Origin on Conflict Style. 


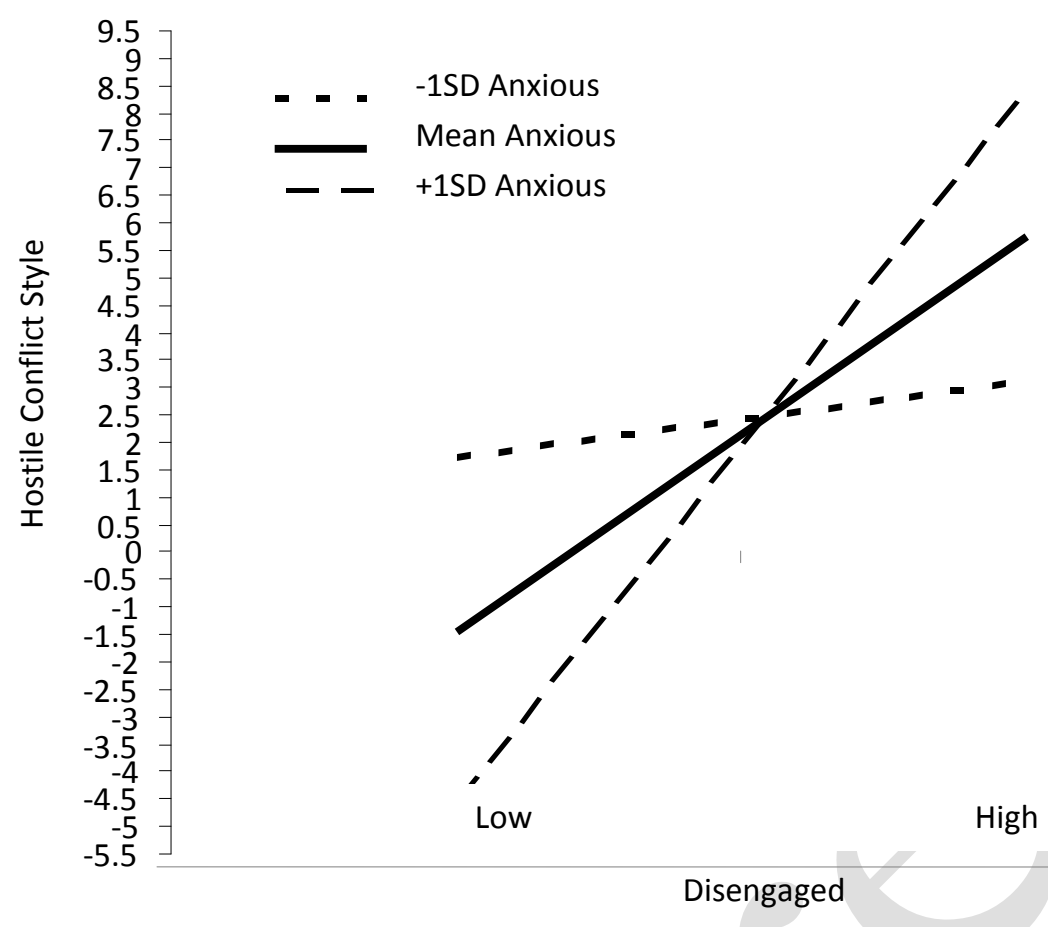

Figure 2. The Moderating Role of Anxious Attachment in the Relationship between Disengaged Family-of-Origin and Hostile Conflict Style.

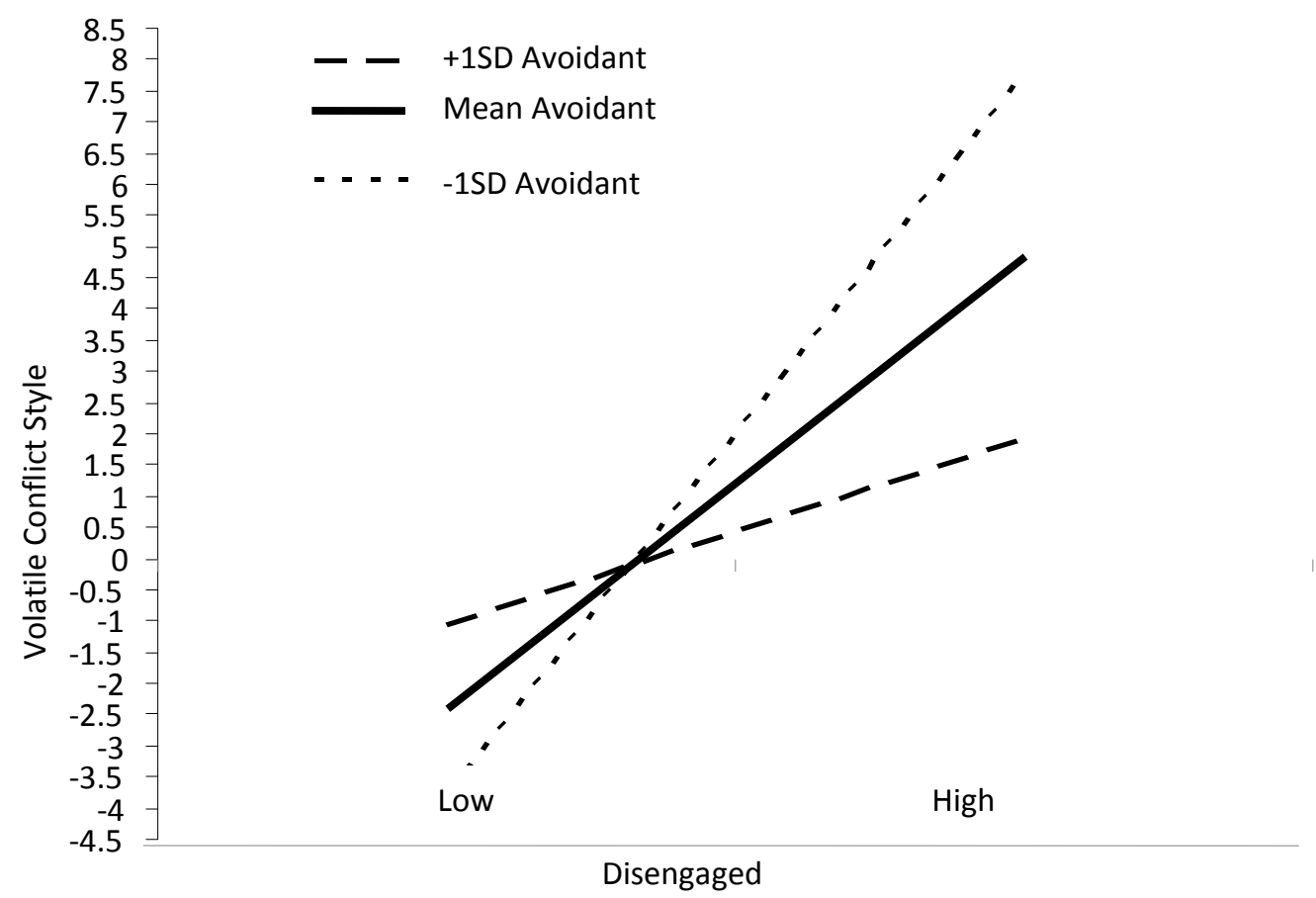

Figure 3. The Moderating Role of Avoidant Attachment in the Relationship between Disengaged Family-of-Origin and Volatile Conflict Style. 
Table 1. Summary of Intercorrelations of Study Variables $(n=190)$.

\begin{tabular}{|c|c|c|c|c|c|c|c|c|c|c|}
\hline Study Variables & 1 & 2 & 3 & 4 & 5 & 6 & 7 & 8 & 9 & 10 \\
\hline 1. Sex & - & & & & & & & & & \\
\hline $\begin{array}{l}\text { 2. Relationship } \\
\text { Status }\end{array}$ & 0.03 & - & & & & & & & & \\
\hline $\begin{array}{l}\text { 3. Anxious } \\
\text { Attachment }\end{array}$ & -0.11 & $-0.40 * * *$ & - & & & & & & & \\
\hline $\begin{array}{l}\text { 4. Avoidant } \\
\text { Attachment }\end{array}$ & $-0.16^{*}$ & $-0.46 * * *$ & $0.64 * * *$ & - & & & & & & \\
\hline 5. Disengaged & $-0.19 * *$ & 0.08 & $0.30 * * *$ & $0.33 * * *$ & - & & & & & \\
\hline 6. Enmeshed & $-0.32 * * *$ & 0.09 & $0.28 * * *$ & $0.30 * * *$ & $0.43 * * *$ & & & & & \\
\hline 7. Volatile & -0.07 & 0.06 & 0.13 & 0.03 & $0.23 * * *$ & $0.18 * *$ & - & & & \\
\hline 8. Avoiding & $-0.17 *$ & -0.11 & $0.18^{*}$ & $0.18 *$ & 0.03 & 0.10 & 0.05 & - & & \\
\hline 9. Validating & -0.01 & $0.21 * *$ & $-0.21 * *$ & $-0.28 * * *$ & $-0.19 * *$ & -0.10 & $-0.15^{*}$ & $0.15^{*}$ & - & \\
\hline 10. Hostile & $-0.26 * * *$ & $-0.18 * *$ & $0.34 * * *$ & $0.37 * * *$ & $0.35 * * *$ & $0.23^{* *}$ & $0.36 * * *$ & 0.02 & $-.38 * * *$ & - \\
\hline$M$ & & & 53.83 & 44.77 & 15.01 & 13.68 & 2.49 & 2.57 & 3.56 & 1.70 \\
\hline$S D$ & & & 21.29 & 20.10 & 5.00 & 4.09 & 1.19 & 1.16 & 1.04 & 1.09 \\
\hline
\end{tabular}

$* p<0.05 . * * p<0.01 . * * * p<0.001$. 
Table 2. Hierarchical Regression Results for Perceived Levels of Enmeshment and Disengagement in Families-ofOrigin and Anxious and Avoidant Attachment on Conflict Style.

\begin{tabular}{|c|c|c|c|c|c|c|c|}
\hline \multirow{2}{*}{$\begin{array}{l}\text { Conflict } \\
\text { Style }\end{array}$} & \multirow[b]{2}{*}{ Variables } & \multicolumn{3}{|c|}{ Model $1^{\mathrm{a}}$} & \multicolumn{3}{|c|}{ Model $2^{b}$} \\
\hline & & $B$ & $S E B$ & $\beta$ & $B$ & $S E B$ & $\beta$ \\
\hline \multirow[t]{10}{*}{ Hostile: } & $\mathrm{CO}^{\mathrm{c}}: \mathrm{Sex}$ & -.484 & .191 & $-.177 * *$ & -.462 & .183 & $-.168 * *$ \\
\hline & CO: Relationship Status & -.445 & .147 & $-.201 * *$ & -.223 & .171 & -.101 \\
\hline & $\mathrm{IV}^{\mathrm{d}}$ : Disengaged & .067 & .016 & $.308^{* * *}$ & .052 & .017 & $.238 * *$ \\
\hline & IV: Enmeshed & .014 & .020 & .054 & -.024 & .021 & -.091 \\
\hline & $\mathrm{MO}^{\mathrm{e}}$ : Anxious & & & & .006 & .004 & .110 \\
\hline & MO: Avoidant & & & & .009 & .005 & .158 \\
\hline & $\mathrm{XO}^{\mathrm{f}}$ : Anxious x Disengaged & & & & .003 & .001 & $.382 * *$ \\
\hline & XO: Anxious x Enmeshed & & & & -.001 & .001 & -.126 \\
\hline & XO: Avoidant x Enmeshed & & & & .001 & .001 & .136 \\
\hline & XO: Avoidant $\mathrm{x}$ Disengaged & & & & -.001 & .001 & -.173 \\
\hline \multirow[t]{10}{*}{ Volatile: } & $\mathrm{CO}^{\mathrm{c}}: \mathrm{Sex}$ & -.002 & .226 & -.001 & -.029 & .227 & -.010 \\
\hline & CO: Relationship Status & .083 & .174 & .034 & .054 & .212 & .022 \\
\hline & $\mathrm{IV}^{\mathrm{d}}$ : Disengaged & .045 & .019 & $.188^{*}$ & .046 & .020 & $.192 *$ \\
\hline & IV: Enmeshed & .027 & .024 & .094 & .032 & .026 & .112 \\
\hline & $\mathrm{MO}^{\mathrm{e}}$ : Anxious & & & & .008 & .005 & .144 \\
\hline & MO: Avoidant & & & & -.007 & .006 & -.120 \\
\hline & $X \mathrm{O}^{\mathrm{f}}$ : Anxious x Disengaged & & & & .002 & .001 & .174 \\
\hline & XO: Anxious x Enmeshed & & & & -.001 & .001 & -.133 \\
\hline & XO: Avoidant x Enmeshed & & & & .001 & .001 & .114 \\
\hline & XO: Avoidant x Disengaged & & & & -.002 & .001 & $-.246^{*}$ \\
\hline \multirow[t]{10}{*}{ Validating: } & $\mathrm{CO}^{\mathrm{c}}: \mathrm{Sex}$ & -.183 & .193 & -.070 & -.137 & .193 & -.052 \\
\hline & CO: Relationship Status & .492 & .149 & $.234^{* * *}$ & .303 & .181 & .144 \\
\hline & $\mathrm{IV}^{\mathrm{d}}$ : Disengaged & -.041 & .016 & $-.195 * *$ & -.038 & .017 & $-.184 *$ \\
\hline & IV: Enmeshed & -.016 & .020 & -.062 & -.002 & .022 & -.009 \\
\hline & $\mathrm{MO}^{\mathrm{e}}$ : Anxious & & & & -.001 & .005 & -.025 \\
\hline & MO: Avoidant & & & & -.008 & .005 & -.152 \\
\hline & $\mathrm{XO}^{\mathrm{f}}$ : Anxious x Disengaged & & & & -.001 & .001 & -.183 \\
\hline & XO: Anxious x Enmeshed & & & & .003 & .001 & $.323 *$ \\
\hline & XO: Avoidant x Enmeshed & & & & -.002 & .001 & -.160 \\
\hline & XO: Avoidant x Disengaged & & & & .001 & .001 & .067 \\
\hline \multirow[t]{10}{*}{ Avoiding: } & $\mathrm{CO}^{\mathrm{c}}: \mathrm{Sex}$ & -.433 & .222 & $-.148^{*}$ & -.416 & .225 & -.142 \\
\hline & CO: Relationship Status & -.254 & .171 & -.108 & -.033 & .210 & -.014 \\
\hline & $\mathrm{IV}^{\mathrm{d}}$ : Disengaged & -.005 & .019 & -.022 & -.018 & .020 & -.077 \\
\hline & IV: Enmeshed & .021 & .024 & .073 & .006 & .026 & .021 \\
\hline & $\mathrm{MO}^{\mathrm{e}}$ : Anxious & & & & .005 & .005 & .094 \\
\hline & MO: Avoidant & & & & .007 & .006 & .116 \\
\hline & $X^{f}$ : Anxious x Disengaged & & & & .000 & .001 & .030 \\
\hline & XO: Anxious x Enmeshed & & & & .000 & .001 & .045 \\
\hline & XO: Avoidant x Enmeshed & & & & .000 & .001 & -.031 \\
\hline & XO: Avoidant x Disengaged & & & & .000 & .001 & -.024 \\
\hline
\end{tabular}

${ }^{a}$ Step 2 regression results. ${ }^{b}$ Step 4 regression results. ${ }^{c}$ Control variable. ${ }^{\mathrm{d}}$ Independent variable. ${ }^{\mathrm{e}}$ Moderator.

finteraction between IV and MO. *p $<.05 . * * p<.01 . * * * p<.001$. 